\title{
Analysis of severe convective events from two operational dual polarisation doppler radars
}

\author{
M. Celano ${ }^{1,2}$, P. P. Alberoni ${ }^{1}$, V. Levizzani ${ }^{3}$, and A. R. Holt ${ }^{4}$ \\ ${ }^{1}$ ARPA-SIM, viale Silvani 6, 40122, Bologna, Italy \\ ${ }^{2}$ Università degli Studi di Ferrara, Dip. di Fisica, via Saragat 1, 44100 Ferrara, Italy \\ ${ }^{3}$ ISAC-CNR, via Gobetti 101, 40129 Bologna, Italy \\ ${ }^{4}$ University of Essex, Dept. of Math. Sciences, Colchester, CO4 3SQ, UK
}

Received: 8 December 2005 - Revised: 22 February 2006 - Accepted: 22 February 2006 - Published: 23 May 2006

\begin{abstract}
The recent gradual increase in the use of polarimetric radars prompts for possible improvements in the estimation of precipitation and the identification of the prevailing hydrometeor type. An analysis of different convection episodes (20 May 2003, 4 and 7 May 2004) is conducted in order to explore the attenuation effects at $\mathrm{C}$ band and their consequences on the rainfall field estimation using two polarimetric radars in the Po Valley, Italy, located about $90 \mathrm{~km}$ apart. A hydrometeor classification scheme, developed at the National Severe Storms Laboratory (NSSL), is used to detect the microphysical structure of the different cloud systems. The work is focused on the reconstruction of the 3-D organisation of the convective events, highlighting how the two radar systems "see" the storms from different points of view. Furthermore, the two distinct observations and the temperature field are used to correct the effect of attenuation.
\end{abstract}

\section{Introduction}

Polarimetric radars are sensitive to hydrometeor properties as size, shape, orientation, and thermodynamic phase (Doviak and Zrnić 1993), and for this reason are expected to play an important role in improving quantitative precipitation estimates through a better estimation of rain patterns (pioneering work of Seliga and Bringi, 1976), validation of nonhydrostatic models, and improvement of initial conditions and constraints in numerical weather prediction (NWP) models for short term forecasts. Moreover, the identification of hydrometeor types has important applications for operational monitoring such as hail warning (e.g., Aydin et al., 1986), and in diagnosing meteorological phenomena with a potential impact in limited area models (LAM) initialisation.

Correspondence to: M. Celano

(mcelano@ arpa.emr.it)
A summary of the state-of-the-art of polarimetry for weather radars can be found in the work of Zrnić and Ryzhkov (1999). To date most of the available literature on radar polarimetry dwells on S-band radars (e.g., Vivekanandan et al., 1999), but the perspective of the deployment of C-band polarimetric radars in Europe motivates the research community to a close examination of the observation capabilities at these wavelengths.

The study is carried out using two polarimetric C-band radars located $90 \mathrm{~km}$ apart in the Po Valley of Northern Italy, in S. Pietro Capofiume (SPC hereafter) and Gattatico (GAT), both managed by ARPA Emilia-Romagna. Radar data at $\mathrm{C}$ or X-band are more affected by attenuation and resonance (Chandra et al., 1995; Upton and Fernandez-Duran, 1999; Zrnić et al., 2000) than those at longer wavelengths. Therefore, a combined scanning strategy of the two instruments was applied as a way of reconstructing the 3-D structure of the cloud systems, concentrating on convective episodes taking place over the area between them.

The analysis focuses on 1) a thorough reconstruction of the attenuation effects (especially differential attenuation) occurring at C-band and their consequences on hydrometeor classification, 2) an investigation on how the two radar systems "see" the storm from different points of view, and 3) a reconstruction of the 3-D storm structure for correcting for the attenuation.

\section{Particle identification algorithms}

The hydrometeor classification algorithm used for the analysis (Galletti et al., 2005) belongs to the fuzzy logic family and is a further implementation of the scheme developed at the National Severe Storms Laboratory (NSSL) (Zrnić at al., 2001) with a reduced set of polarimetric variables collected at C-band: reflectivity (Z) and differential reflectivity (ZDR).

Published by Copernicus GmbH on behalf of the European Geosciences Union. 

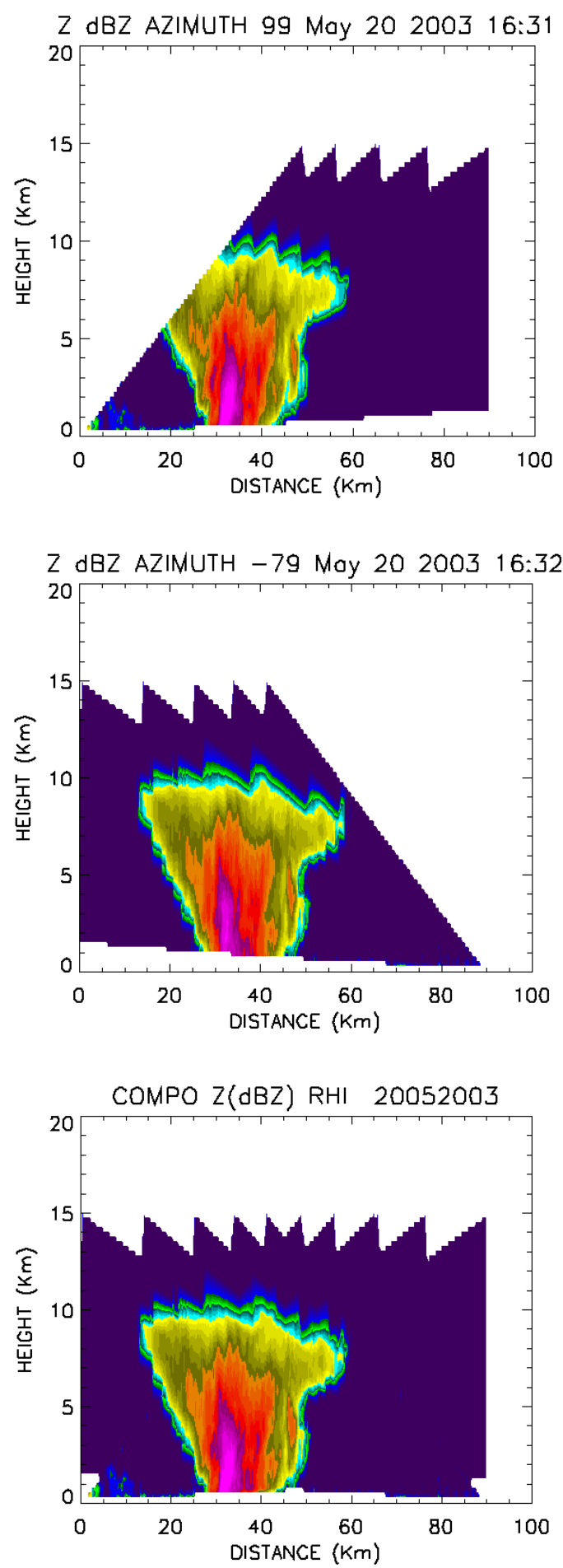
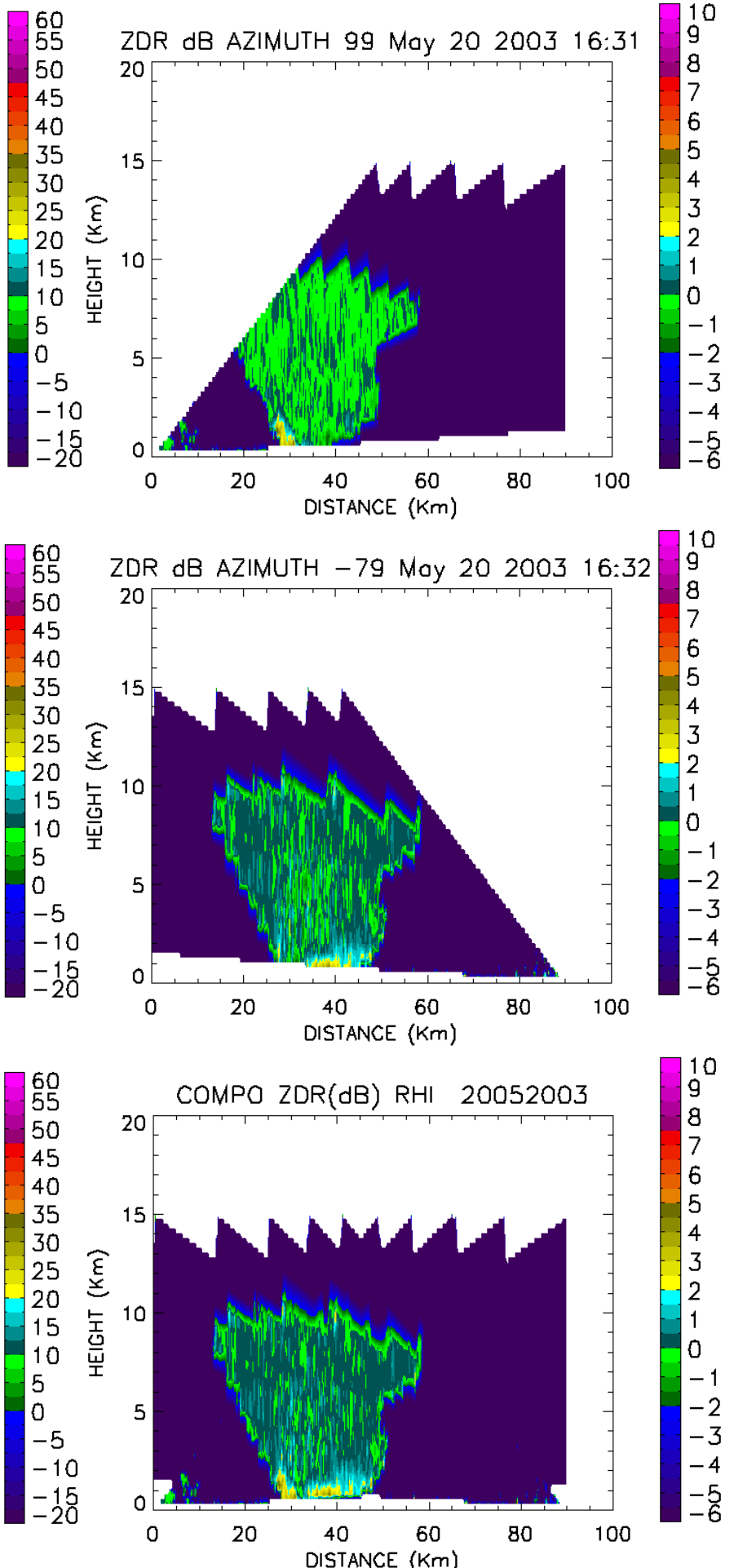

Fig. 1. 20 May 2003; RHI of Z and ZDR for the GAT radar (a), (b), the SPC radar (c), (d) and the composite (e), (f) along the reference line connecting the two radars.

The fuzzy logic-based methodology was applied in the first place for implementing capabilities of distinguishing be- tween several classes/types of hydrometeors. The crucial point of the classification scheme is the partitioning of the 

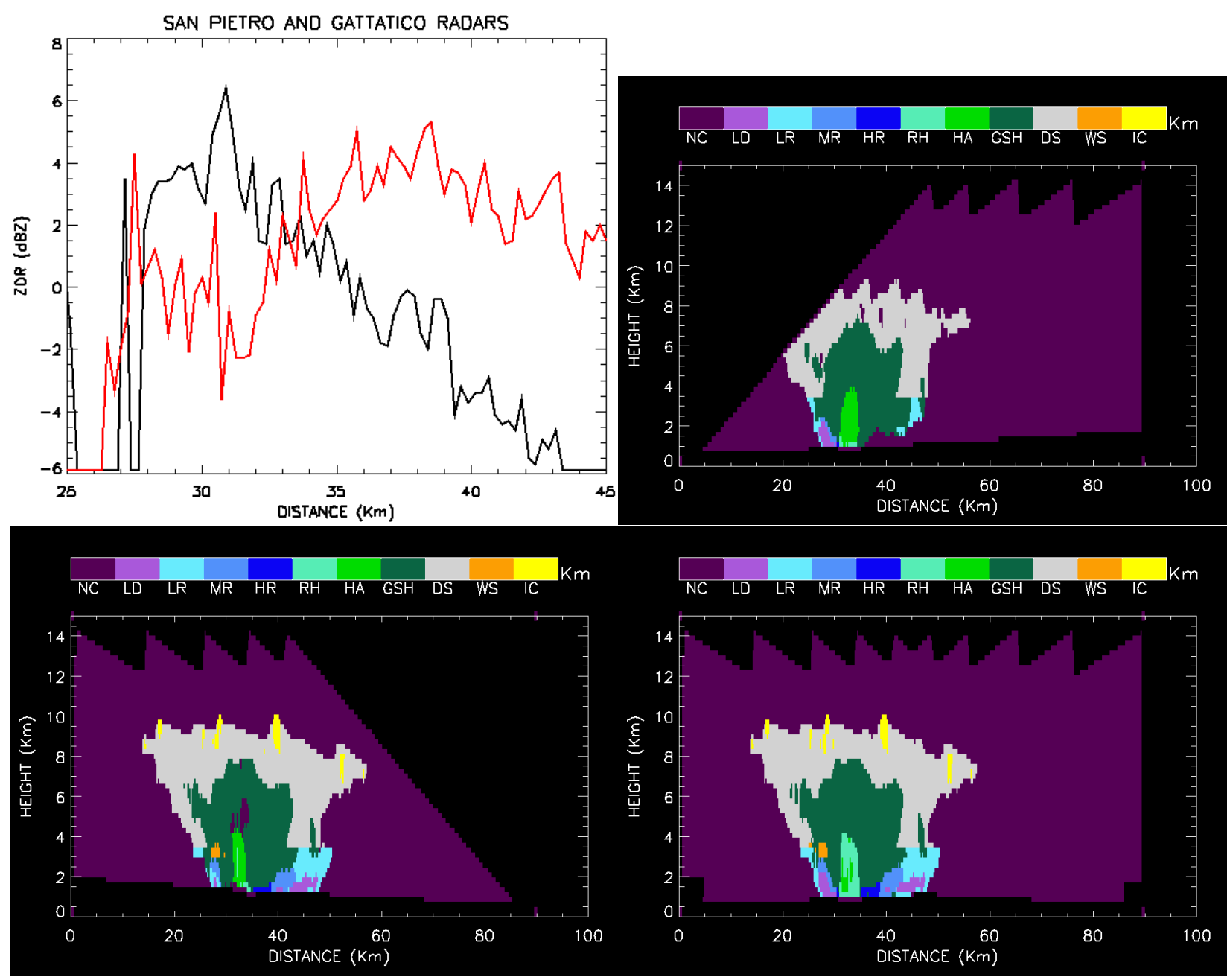

Fig. 2. 20 May 2003; (a) ZDR first elevation ray for the GAT (black line) and the SPC radar (red line) along the reference line. RHI hydrometeors classification for (b) GAT, (c) SPC radars and the composite (d).

multidimensional space generated by the polarimetric variables in subsets related to specific particle classes. The scheme is based on a combination of weighting functions that map the Z-ZDR space and that are associated with a particular type of hydrometeor. These weighting functions have a trapezoidal shape (a 3-D graph would appear as a truncated pyramid with lower base at 0 and upper base at 1) whose variables are the horizontal reflectivity $\mathrm{ZH}$ and the differential reflectivity ZDR that show the highest discriminating power for the classification process. In analogy with the probability density functions (PDF), the membership functions are the product of a 1-dimensional weighting function for $\mathrm{ZH}\left[\mathrm{W}_{j}(\mathrm{ZH})\right]$ by a conditional weighting function for ZDR [W $\left.{ }_{j}(\mathrm{ZDR}, \mathrm{ZH})\right]$, and they decrease linearly with distance from 1 to 0 along the "fuzzy boundaries". The two-dimensional polarimetric membership functions over the ZH-ZDR space, developed for S-band radars, are described by Straka et al. (2000). Galletti et al. (2005) provide a short description of the functions for the C-band applications. The environmental temperature is used to remove ambiguities in the decision process by introducing the additional constraint that every class of hydrometeors can only be found in cloud a within a certain range of temperatures (e.g., dry snow or ice crystals are not found at temperatures above zero). The scheme makes use of a standard atmospheric profile of 6.5 $\mathrm{km}^{-1}$ starting from the surface temperature measured by local groundstations. The integration of temperature in the classification scheme thus helps considerably in discarding unreasonable results stemming from computational artifacts.

The algorithm can be expressed as:

$S_{j}=\frac{\mathrm{W}_{j}(\mathrm{ZDR}, \mathrm{ZH}) \mathrm{W}_{\mathrm{pol}}+\mathrm{W}_{j}(T) \mathrm{W}_{T}}{\mathrm{~W}_{\mathrm{pol}}+\mathrm{W}_{T}}$

where $\mathrm{j}$ is the $\mathrm{j}$-th hydrometeor class, $\mathrm{S}_{j}$ the threshold value, $\mathrm{W}_{j}(\mathrm{ZDR}, \mathrm{ZH})$ the polarimetric membership function, $\mathrm{W}_{j}(\mathrm{~T})$ the temperature membership function, and $\mathrm{W}_{\mathrm{pol}}$ and $\mathrm{W}_{T}$ 

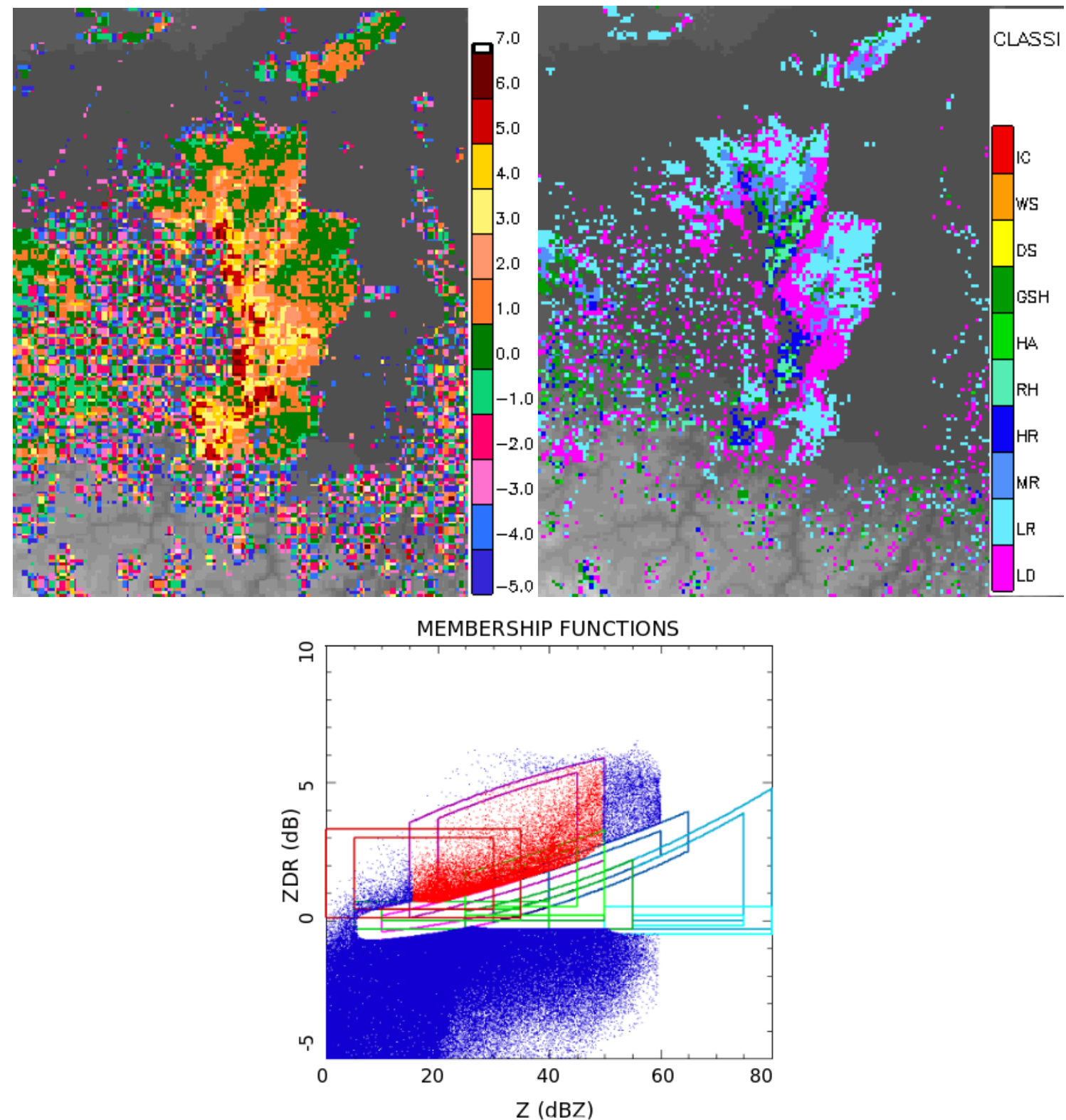

Fig. 3. 20 May 2003; (a) First elevation PPI composite of ZDR. (b) First elevation PPI composite of hydrometeor classification. (c) Location in the ZH-ZDR domain (membership functions) of the unclassified cells (blue) and the large-drop cells (red) for both GAT and SPC radars.

multiplicative factors $(\leq 1)$ that define the relative importance of each variable.

The assignment to a class is accomplished by taking the highest value of the combination of weighting functions. In other words, each image pixel is associated with the hydrometeor class that maximizes the threshold $\mathrm{S}_{j}$. In our scheme the multiplicative factors are set to 1 and the minimum acceptable threshold is 0.55 .

An attempt to discriminate between ten hydrometeor classes is made: light rain $\left(\mathrm{LR},<5 \mathrm{~mm} \mathrm{~h}^{-1}\right)$, moderate rain
(MR, 5-30 $\left.\mathrm{mm} \mathrm{h}^{-1}\right)$, heavy rain $\left(\mathrm{HR},>30 \mathrm{~mm} \mathrm{~h}^{-1}\right)$, large drops ( $\mathrm{LD}$, when the raindrop size distribution is dominated by a very low concentration of large drops), rain-hail mixture (RH), graupel-small hail (GSH), hail (HA), dry snow (DS), wet snow (WS), and ice crystals (IC). However, note that the method was originally conceived for S-band radars with an enlarged set of polarimetric parameters. On some occasions, the 10-type classification may result overly optimistic. 


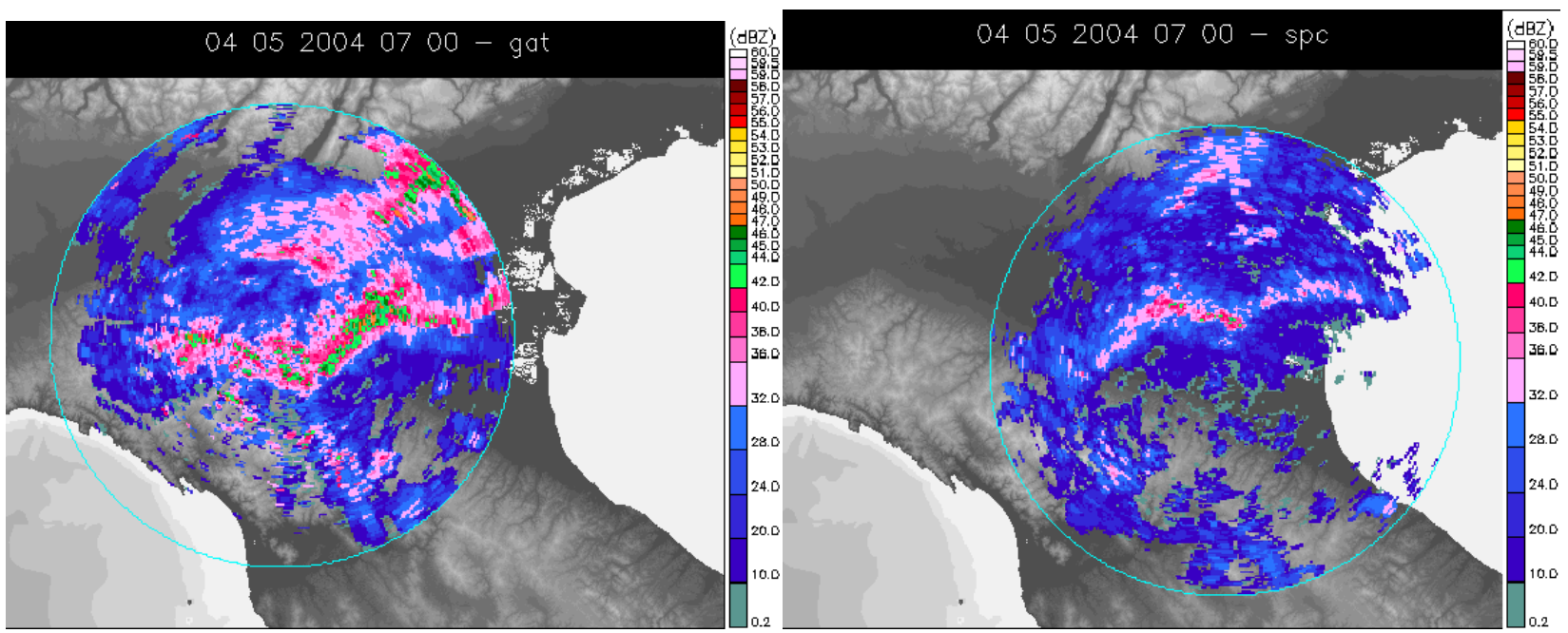

Fig. 4. 4 May 2004; ZLR maps for the GAT (a) and the SPC radars (b).

\section{Case studies}

\subsection{May 2003 - Deep convection}

During the night of 19/20 May 2003 a cold front, approaching from NW and moving across the Alps, caused a deep convective event in the flat lands of North-Eastern Italy. A severe hailstorm with very large hail hit the area monitored by the two radars.

Figure 1 displays the $\mathrm{Z}$ and ZDR RHI vertical slice through the storm for GAT (Figs. 1a, b) and SPC (Figs. 1c, d) radars along the reference line connecting the two radars.

The core of the storm, characterized by high values of $\mathrm{Z}(50<\mathrm{Z}<60 \mathrm{dBZ})$, is located about $55-60 \mathrm{~km}$ from SPC and $30-35 \mathrm{~km}$ from GAT. Note the different attenuation zones in the ZDR maps within the two regions behind the convective core, depending on the different radar viewing angles. The attenuation signature is clearly highlighted by analysing the first elevation rays of ZDR from each radar along the reference line (Fig. 2a, red line for SPC and black line for GAT).

The SPC+GAT Z and ZDR RHI composite maps are shown in Figs. 1e, f. The composite map is made by taking the highest values of $\mathrm{Z}$ and ZDR for each image pixel trying to correct for the attenuation effect. The matching of the two radar data is a critical step, depending on the position of the storm with respect to the radars. Differences in $\mathrm{Z}$ and ZDR can be attributed to attenuation effects, but also to the fact that the radars see different parts of the storm. How exactly to carry on the data matching is still an open problem and it will be a subject of further investigation.

The hydrometeor classification for GAT (Fig. 2b) and SPC (Fig. 2c) radars are shown together with the final classification (Fig. 2d) using the two sets of radar data. The SPC and GAT maps describe how the microphysics is detected by the two radar systems, and they confirm that they were scanning the same event, since the two maps look very similar except for the evident attenuation effect. Moreover, the overall classification appears a reasonable reconstruction of the storm. Note that $1 \mathrm{~km}$-smoothed classifications are presented, to reduce the chaotic pattern due to noise. The final matched classification presents the typical concentric structure of a convective event. The presence of hail and rain-hail mixture are well detected in the core of the storm, with graupel around them. Ahead and behind the core there is rain (light, medium, heavy and large drops) close to the ground, and dry snow and ice crystals above the melting layer (where wet snow is correctly detected). Note that the rainfall seen by the SPC radar is only partially seen by the GAT radar, and the two classifications present different unclassified zones.

Another critical point is that, for some hydrometeor classes, the C-band ZDR may be higher than the maximum ZDR value of the membership functions displayed in Fig. 3c $(\sim 6 \mathrm{~dB})$; in this case, the radar cells will remain unclassified (Holt, 1984; Zrnić et al., 2000). The SPC and GAT classification maps do in fact present unclassified regions in correspondence to high values of ZDR. Thus the highest ZDR values in the composite classification delimit unclassified areas, such as the unclassified region all around the storm core correctly filled with hail. Figure $3 \mathrm{c}$ marks the location of the unclassified (blue) and the large-drop cells (red) for both GAT and SPC radars in the ZH-ZDR domain. The unclassified points are connected to the negative bias due to attenuation $(\mathrm{ZDR}<0)$, but also to the very high values of $\mathrm{ZDR}$ that do not fit the S-band membership functions (Fig. 3a displays the composite 0.5 degree elevation PPI for ZDR). This is probably one of the reasons for such an extended largedrop region in the PPI classifications (Fig. $3 b$ shows the first 

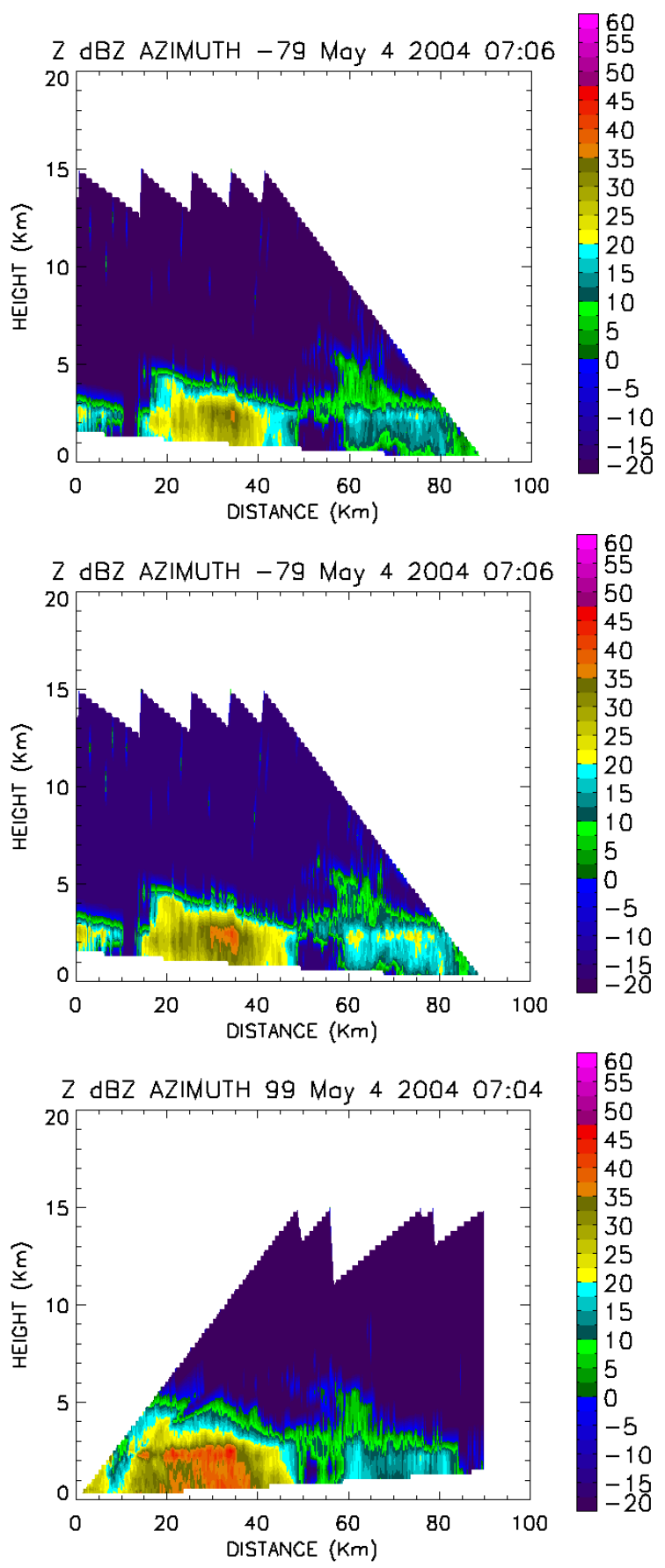

Fig. 5. 4 May 2004; RHI of Z for the SPC radar before (a) and after (b) the bias correction and the GAT radar (c) along the reference line.

elevation PPI $1 \mathrm{~km}$-smoothed composite classification). Zrnic et al. (2000) point out that very large ZDR values can be caused by resonance effects. These occur at about $6 \mathrm{~mm}$ drop size, which may contain ice cores or break around 6-8 $\mathrm{mm}$ size. The algorithm is likely to need modifications taking care of these situations.
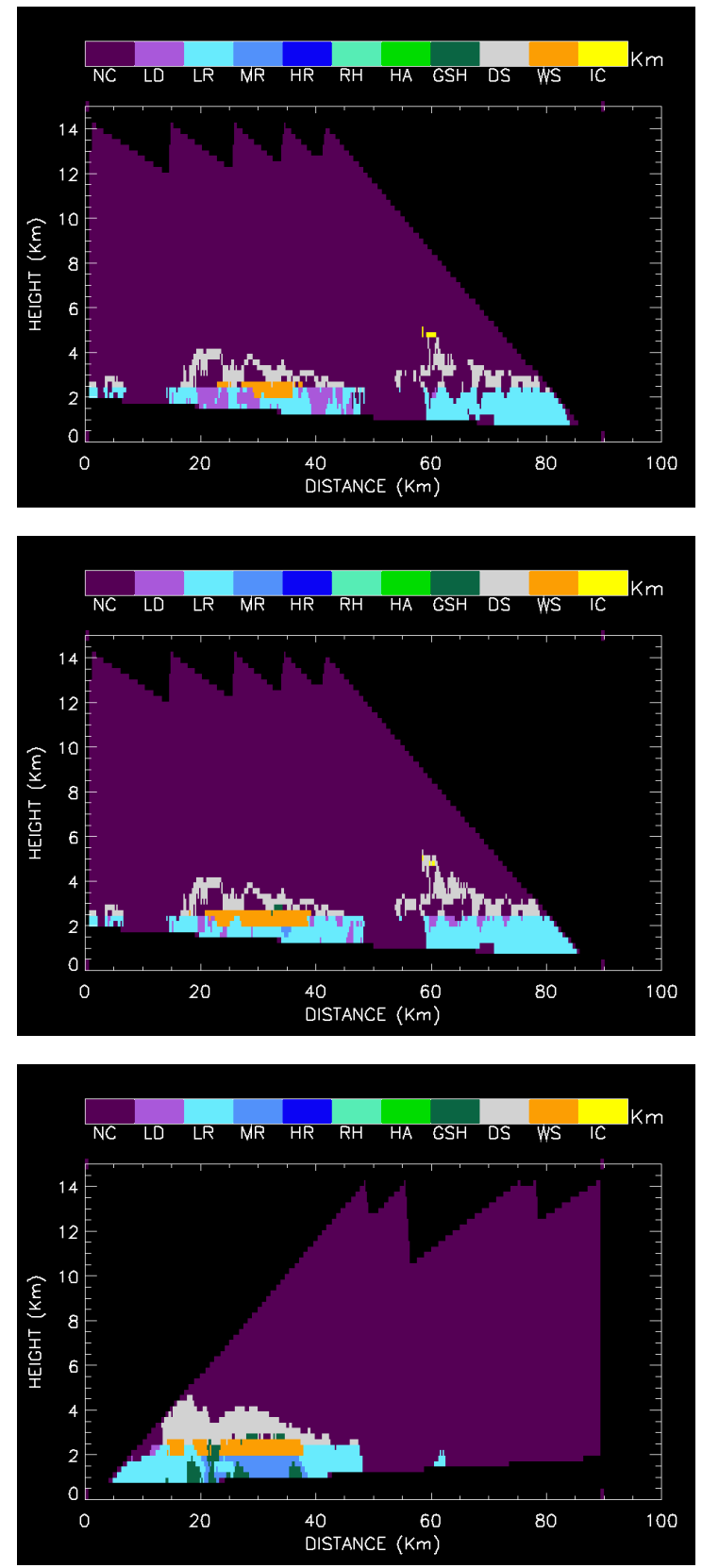

Fig. 6. 4 May 2004; RHI hydrometeor classification for the SPC radar before (a) and after (b) the bias correction and the GAT radar (c) along the reference line.

\subsection{May 2004 - Squall line in a shallow convective event}

On 4 May 2004 a stratiform precipitating system passed over Emilia-Romagna: embedded convective cells were organized into a squall line located (around 07:00 UTC) between SPC and GAT radars and moving towards NW. The ground stations close to the radars reported rainfall during the whole day with surface $\mathrm{T}=14.5^{\circ} \mathrm{C}, \mathrm{p}=996 \mathrm{hPa}$, humidity $=100 \%$, and low visibility. 

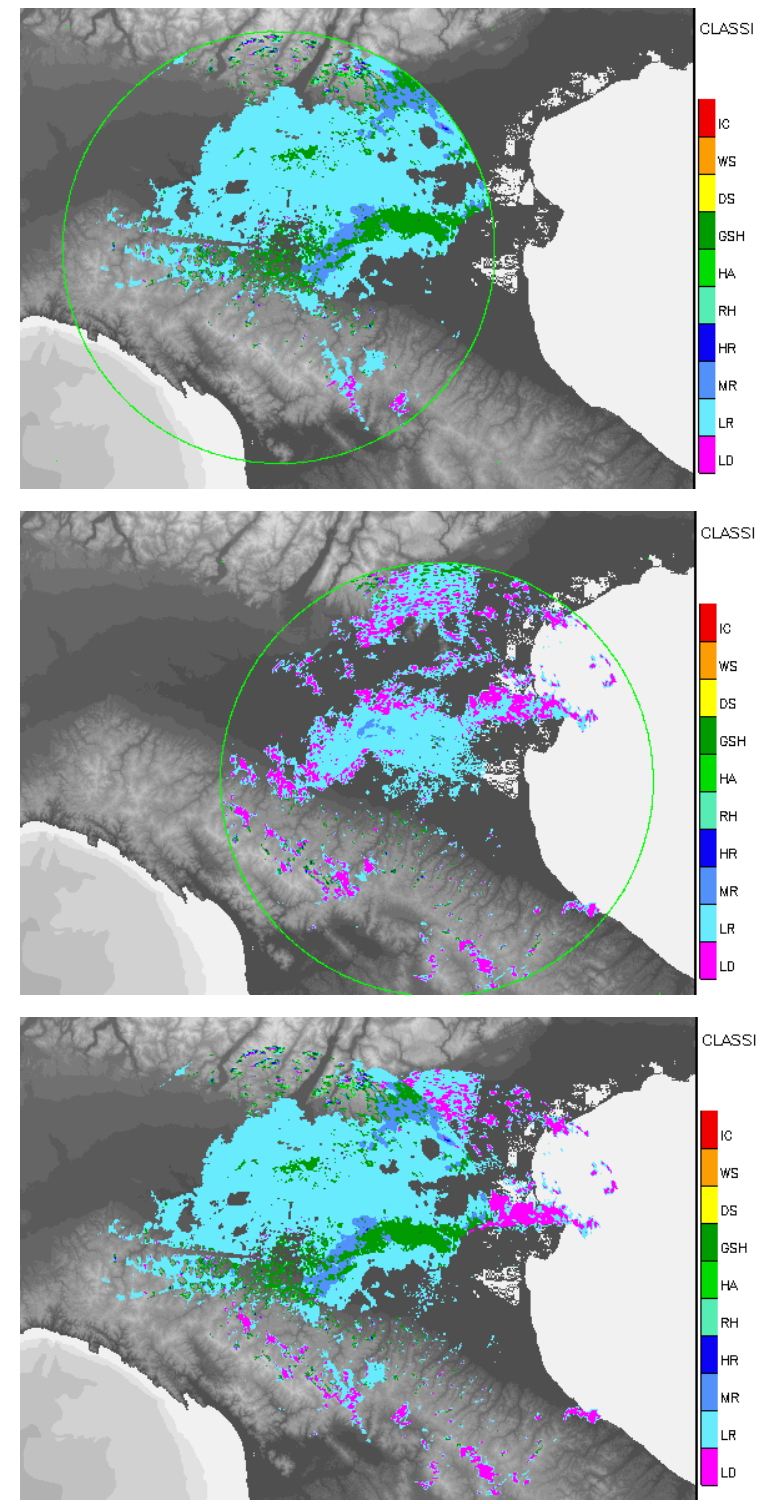

Fig. 7. 4 May 2004; First elevation PPI hydrometeor classification for the GAT radar (a), the SPC radar (b) and the composite classification (c).

In Fig. 4 the "low range reflectivity maps", ZLR, for GAT and SPC radars (i.e., the lowest elevation $\mathrm{Z}$ for each radar beam excluding mountains or other obstacles) are displayed. A negative bias in SPC radar measurements with respect to the GAT ones is evident and shows up in the RHI Z maps (see Figs. 5a and c for SPC and GAT radar, respectively). The power of the SPC radar signal for that day was very low, ranging from $4 \mathrm{~kW}$ for the first beam to $88 \mathrm{~kW}$ (against the optimal range of about $200-400 \mathrm{~kW}$ ), while the power of GAT radar was quite constant (around $400 \mathrm{~kW}$ ). This is probably the main reason that caused the negative bias of $4 \mathrm{~dB}$, especially evident in SPC data more than in GAT ones.
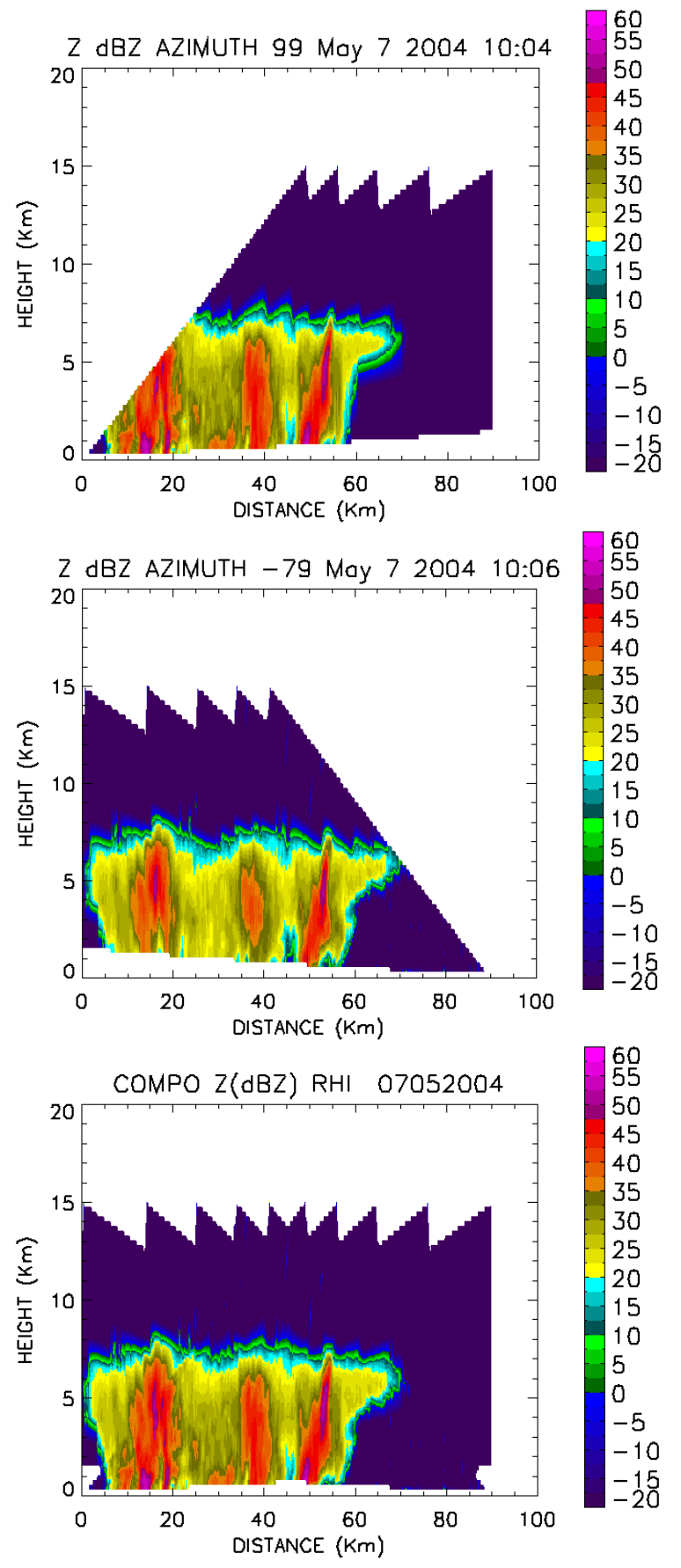

Fig. 8. 7 May 2004; RHI of Z for the GAT radar (a), the SPC radar (b) and the composite (c) along the reference line.

The ZLR maps clearly show the convective squall line with a wing shape embedded in the widespread stratiform event. From a close examination of the RHI Z maps for SPC and GAT radars on the reference line the event presents the typical characteristics of a shallow convective system extending to a maximum height of $5 \mathrm{~km}$. The region of the highest 


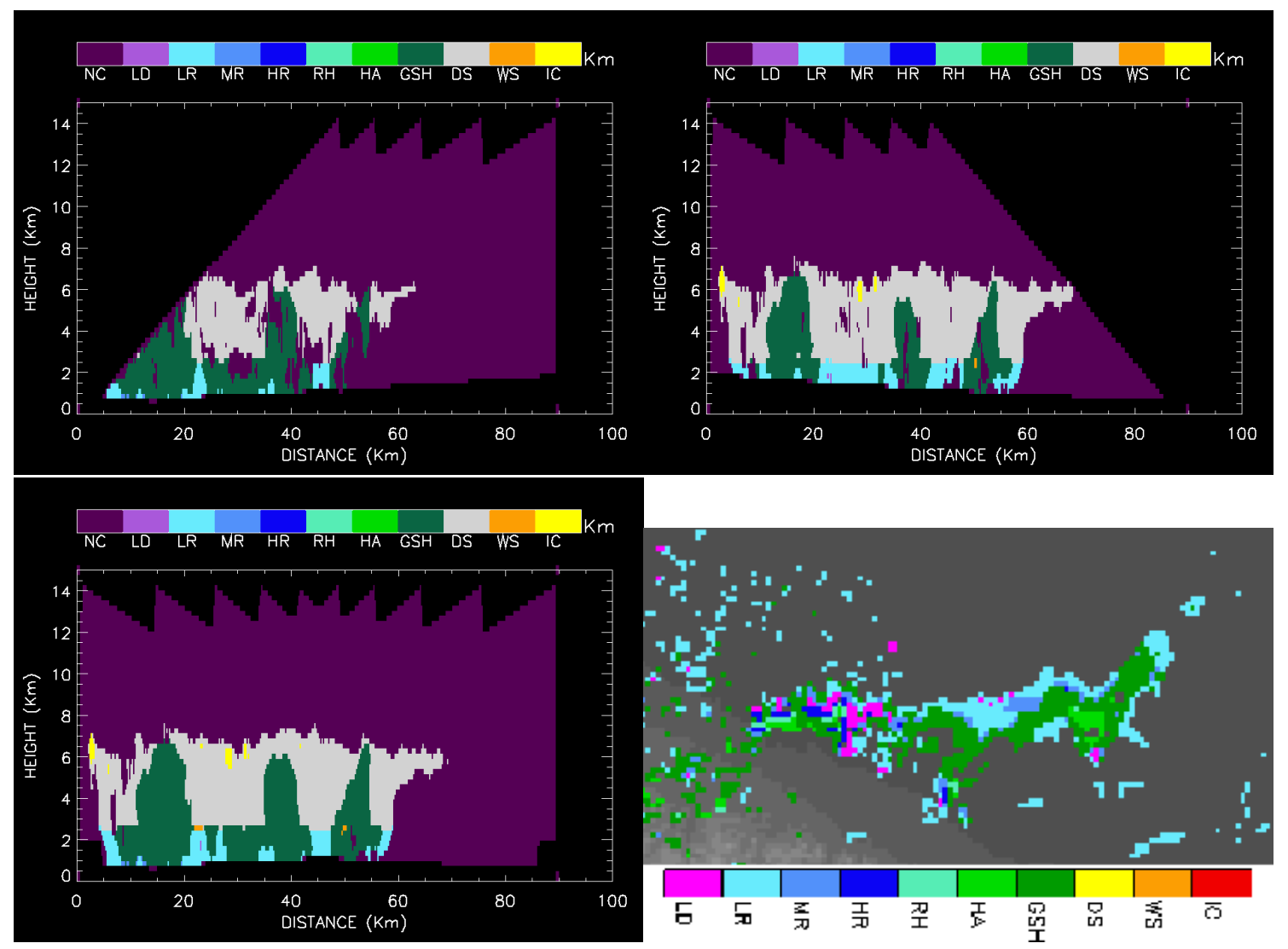

Fig. 9. 7 May 2004; RHI hydrometeor classification for the GAT radar (a), the SPC radar (b) and the composite classification (c) along the reference line. In (d) the first elevation PPI of the composite hydrometeor classification.

$\mathrm{Z}$ value ( $\sim 45 \mathrm{~dB}$, where the squall line is crossed by the radar beam) is located 20 to $40 \mathrm{~km}$ from the GAT radar and 50 to $70 \mathrm{~km}$ from the SPC radar where the bright band is particularly strong at about $2 \mathrm{~km}$ from the ground.

The RHI Z map for SPC after the correction of about $4 \mathrm{~dB}$ negative bias, displayed in Fig. 5b, shows a better description of the system core. The corrected reflectivity is in fact closer to that of the GAT radar. Moreover, a no-rain zone is seen by both radars about $50-60 \mathrm{~km}$ from GAT.

As in the previous event, in the RHI ZDR maps the bright band signal and the different attenuation zones depending on the different views of the two radars are detectable and the $\mathrm{Z}$ and ZDR two-radar composites give a reasonable and a more complete description of the event.

The hydrometeor classification of the GAT radar is shown in Fig. 6c. Wet snow is well detected at the melting layer height, dry snow above, light rain close to the radar and beyond the squall line. Note the heavier precipitation (named medium rain) in the convective cell with some pixels classified as graupel.

The SPC classifications before and after the biascorrection are displayed in Fig. 6a, b. The classification prior to the $\mathrm{Z}$ bias correction indicates the presence of light rain, but there are too many LD, an unrealistic fact for a predominantly stratiform event. The presence of the LD class decreases after the bias correction (Fig. 6b) and the reason is related to the membership function, where a lower value of $\mathrm{Z}$ implies for this case a larger number of pixels falling in the LD instead of the MR class.

The first elevation PPI classification for the GAT radar (Fig. 7a) shows a wide region of light rain with graupel and medium rain along the convective line, while for the SPC radar light-medium rain and LD are detected (Fig. 7b, the amount of LD decreasing after the bias correction).

The composite PPI classification (Fig. 7c) is dominated by the GAT data because it presents a medium-to-high signal and the classification is done by taking the highest reflectivity value. Thus, this final composite classification using data collected by both radars gives a better reconstruction of the squall line; in particular the left part of the line is better described by the GAT radar and the right part by the SPC one. 


\subsection{May 2004 - Multicell thunderstorm}

On 7 May 2004 a multicell thunderstorm over the Apennines moved towards the plain pouring heavy rain and hailfall over the whole Emilia Romagna region. The convective cells presented a wide range of sizes and rain intensities.

Three convective cells lay centred at 15,40 and $50 \mathrm{~km}$ from GAT, and 40, 50 and $75 \mathrm{~km}$ from SPC radar as reported in the RHI Z maps for GAT (Fig. 8a) and SPC (Fig. 8b) along the reference line. The maps of the two radars look very similar and the anvil is well detected on the right side of the storm top about $8 \mathrm{~km}$ above ground. The RHI Z map after matching the two radar fields is shown in Fig. 8c

The hydrometeor identification results (see Figs. 9a, b, c for GAT, SPC and the composite, respectively) show graupel and small hail diagnosed in the convective areas surrounded by light rain or dry snow depending on whether the cells are placed above or below the melting level. The composite RHI classification appears to be reasonable and consistent with the expected microphysical processes in such kind of thunderstorm.

The GAT classification presents more numerous unclassified cells than does the SPC radar. This is connected to a small negative bias of the ZDR data probably due to attenuation or an acquisition problem. After examining the $\mathrm{ZH}$ ZDR domain, the greater part of the unclassified cells falls a little below the membership function named graupel and small hail (ZDR values slightly $<0$ ) that would represent an acceptable hydrometeor class in this case.

Finally, Fig. 9d shows the composite hydrometeor classification for the first elevation PPI that indicates the presence of light, medium, heavy and large drop precipitation, and graupel-small hail around the deepest and most intense cells.

\section{Conclusions}

The analysis confirms that $\mathrm{C}$-band radars are strongly affected by differential attenuation, especially in case of deep convective events.

The composite hydrometeors classification, taking advantage of the different point of view of the two radar systems, appears a reasonable approach to a 3-D-recontruction of different convective events, particularly if they occur along the line connecting the two radars and for the first elevation classification PPI (to avoid to consider significantly different altitudes).

The future development of membership functions purposely created for C-band radar data is deemed of fundamental importance, and will possibly introduce an improvement in the application of the hydrometeor classification algorithm actually in use, which is still very much linked to its original S-band radar environment.
Acknowledgements. This work was partially supported by CARPE DIEM, a research project co-funded by the European Commission under the 5th FP (Contract $N^{o}$ EVG1-CT-2001-0045), and by the INTERREG IIIB CADSES "RISK AWARE" 3B064 project. Particular thanks go to D. Zrnic and A. Ryzhkov for the classification code. Thanks to P. Giordano for producing the power signal radar data.

Edited by: L. Ferraris

Reviewed by: two referees

\section{References}

Aydin, K., Seliga, T. A., and Balaji, V. : Remote sensing of hail with a dual-linear polarization radar, J. Climate Appl. Meteorol., 25, 1475-1484, 1986.

Chandra, M., Wood, S. J., Lux, S. Holt, A. R., and Schroth, A.: Propagation effects in C-band polarisation - diversity measurements, "Cost75 Weather Radar Systems International seminar Brussels”, European Commission Report EUR 16“013 EN, Brussels, 507-518, 1995.

Doviak, R. J. and Zrnić, D. S.: Doppler radar and weather observations, Academic Press. Inc., San Diego, CA, 562, 1993.

Galletti, M., Alberoni, P. P. Levizzani, V., and Celano, M.: Assessment and tuning of the behaviour of a microphysical characterization scheme, Adv. Geosci., 2, 145-150, 2005.

Holt, A. R.: Some factors affecting the remote sensing of rain by polarisation diversity radar in the $3-35 \mathrm{GHz}$ frequency range, Radio Science, 19, 1399-1412, 1984.

Seliga, T. A. and Bringi, V. N.: Potential use of radar differential reflectivity measurements at orthogonal polarizations for measuring precipitation, J. Appl. Meteorol., 15, 69-76, 1976.

Straka, J. M., Zrnić, D. S., and Ryzhkov, A. V.: Bulk hydrometeor classification and quantification using polarimetric radar data: synthesis of relations, J. Appl. Meteorol., 39, 1341-1372, 2000.

Upton, G. and Fernandez-Duran, J. J.: Statistical techniques for clutter removal and attenuation detection in radar reflectivity images, "COST75 Advanced weather radar Systems international seminar Locarno", European Commission, Brussels report EUR 18567 EN, 747-757, 1999.

Vivekanandan, J., Zrnić, D. S., Ellis, S. M., Oye, R., Ryzhkov, A. V., and Straka, J. M.: Cloud microphysics retrieval using Sband dual-polarization radar measurements, Bull. Amer. Meteorol. Soc., 80, 381-388, 1999.

Zrnić, D. S. and Ryzhkov, A. V. : Polarimetry for weather surveillance radars, Bull. Amer. Meteorol. Soc., 80, 389-406, 1999.

Zrnić, D. S., Keenan, T. D., Carey, L. D., and May, P. T. : Sensitivity analysis of polarimetric variables at a $5-\mathrm{cm}$ wavelength in rain, J. Appl. Meteorol., 39, 1514-1526, 2000.

Zrnić, D. S., Ryzhkov, A. V. Straka, J. M., Liu, Y., and Vivekanandan, J.: Testing a procedure for automatic classification of hydrometeor types, J. Atmos. Oceanic Technol., 18, 892-913, 2001. 